\title{
Vitamin D, carotid intima-media thickness and bone structure in patients with type 2 diabetes
}

\author{
Karoline Winckler ${ }^{1}$, Lise Tarnow ${ }^{2,3,4}$, Louise Lundby-Christensen ${ }^{4,5}$, \\ Thomas P Almdal ${ }^{4,6}$, Niels Wiinberg7 ${ }^{7}$ Pia Eiken ${ }^{1,8}$, Trine W Boesgaard ${ }^{4}$ and \\ the CIMT trial group ${ }^{+}$
}

${ }^{1}$ Department of Cardiology, Nephrology and Endocrinology, and ${ }^{2}$ Department of Research, Nordsjaellands Hospital, Nordsjællands University Hospital, Dyrehavevej 29, 3400 Hilleroed, Denmark

${ }^{3}$ Institute of Clinical Studies, University of Aarhus, Aarhus, Denmark

${ }^{4}$ Clinical Research Unit, Steno Diabetes Center, Gentofte, Denmark

${ }^{5}$ Department of Paediatrics, Hvidovre Hospital, Copenhagen University Hospital, Hvidovre, Denmark

${ }^{6}$ Department of Medicine, Copenhagen University Hospital, Gentofte, Denmark

${ }^{7}$ Department of Physiology and Nuclear Medicine, Frederiksberg Hospital, Copenhagen University Hospital, Frederiksberg, Denmark

${ }^{8}$ Institute of Clinical Medicine, University of Copenhagen, Copenhagen, Denmark

${ }^{\dagger}$ The members of the CIMT trial group are listed in the Acknowledgements section

\author{
Correspondence \\ should be addressed \\ to K Winckler \\ Email \\ Karoline.winckler.01@ \\ regionh.dk
}

\begin{abstract}
Despite aggressive treatment of cardiovascular disease (CVD) risk factors individuals with type 2 diabetes (T2D) still have increased risk of cardiovascular morbidity and mortality. The primary aim of this study was to examine the cross-sectional association between total (25-hydroxy vitamin D (25(OH)D)) and risk of CVD in patients with T2D. Secondary objective was to examine the association between 25(OH)D and bone health. A Danish cohort of patients with T2D participating in a randomised clinical trial were analysed. In total 415 patients (68\% men, age $60 \pm 9$ years (mean \pm s.D.), duration of diabetes $12 \pm 6$ years), including 294 patients (71\%) treated with insulin. Carotid intima-media thickness (IMT) and arterial stiffness (carotid artery distensibility coefficient (DC) and Young's elastic modulus (YEM)) were measured by ultrasound scan as indicators of CVD. Bone health was assessed by bone mineral density and trabecular bone score measured by dual energy X-ray absorptiometry. In this cohort, 214 patients (52\%) were vitamin D deficient (25(OH)D $<50 \mathrm{nmol} / \mathrm{l}$ ). Carotid IMT was $0.793 \pm 0.137 \mathrm{~mm}$, DC was $0.0030 \pm 0.001 \mathrm{mmHg}$, YEM was $2354 \pm 1038 \mathrm{mmHg}$ and $13(3 \%)$ of the patients were diagnosed with osteoporosis. A $25(\mathrm{OH})$ D level was not associated with carotid IMT or arterial stiffness $(P>0.3)$ or bone health $(P>0.6)$ after adjustment for CVD risk factors. In conclusion, 25(OH)D status was not associated with carotid IMT, arterial stiffness or bone health in this cohort of patients with T2D. To explore these associations and the association with other biomarkers further, multicentre studies with large numbers of patients are required.
\end{abstract}

\section{Key Words}

- carotid intima-media thickness

- 25-hydroxyvitamin D

- bone structure

- cardiovascular disease and type 2 diabetes

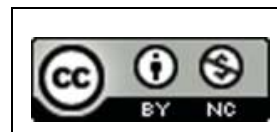

This work is licensed under a Creative Commons Attribution-NonCommercial 4.0 International License. 


\section{Introduction}

Despite aggressive treatment of cardiovascular disease (CVD) risk factors individuals with type 2 diabetes (T2D) still have an about twofold increased risk of cardiovascular morbidity and mortality compared to the general population $(1,2,3)$.

Carotid intima-media thickness (IMT) measured by ultrasound has in several epidemiological studies been demonstrated to be associated with prevalent CVD and is considered an independent predictor of future CVD events like myocardial infarction (MI), stroke and death. Carotid IMT has therefore been suggested as a suitable surrogate marker for CVD in the general population $(4,5)$ and in patients with T2D (6). Carotid artery distensibility coefficient (DC) and Young's elastic modulus (YEM) are markers of arterial stiffness and has been shown to correlate well with overall cardiovascular outcome $(7,8)$. DC represents a global stiffness measurement of the entire arterial wall based on a single measurement site, whereas YEM can detect more subtle changes in the relative proportions of the layering of the arterial wall $(9,10)$

A number of studies indicate a high prevalence of vitamin $\mathrm{D}$ deficiency in the general population and diabetic cohorts $(11,12)$. Several epidemiological studies have reported an association between vitamin D deficiency and risk of CVD including hypertension, hyperlipidemia, carotid IMT, arterial stiffness, MI and obesity $(13,14,15)$. Few studies have examined the association between vitamin D status and risk of CVD in patients with T2D $(16,17)$, and one study has reported an association between low 25-hydroxy vitamin D (25(OH)D) and increased carotid IMT in patients with T2D (18). In contrast, sufficient levels of vitamin $\mathrm{D}$ has been linked to improved endothelial function, inhibition of foam cell formation and suppression of macrophage cholesterol uptake in patients with T2D $(19,20)$.

Vitamin D's effect on bone health (fractures and bone mineral density (BMD)) is well established in the general population (21), while data from epidemiological studies in persons with diabetes - being less conclusive - suggest that vitamin $\mathrm{D}$ deficiency predisposes to $\beta$ cell dysfunction, insulin resistance and T2D (11). Patients with T2D have increased risk of hip $(22,23)$, spine and extremity fractures (24) despite normal or increased BMD (25).

We hypothesize, that low $25(\mathrm{OH}) \mathrm{D}$ is associated with risk of CVD and reduced bone health.

This cross-sectional study aims to investigate the complex relationship between $25(\mathrm{OH}) \mathrm{D}$, risk of CVD (measured as carotid IMT, carotid artery DC and YEM) and bone health (measured as BMD and trabecular bone score (TBS)) in a Danish cohort of patients with T2D participating in a randomised clinical trial (The Copenhagen Insulin and Metformin Therapy (CIMT) trial) (26).

\section{Materials and methods}

The CIMT trial is an investigator-initiated, multicentre, randomised controlled study with a $2 \times 3$ factorial design. The trial was initiated in May 2008 and completed in December 2012 at eight hospitals in the Region of Copenhagen, Denmark, in accordance with ICH-GCP regulations and the Helsinki Declaration (trial registration ClinicalTrials.gov number NCT00657943) and approved by the Ethical Committee. Patients were recruited from diabetes clinics and signed informed consent if they met the following inclusion criteria: age $>30$ years, BMI between 25 and $40 \mathrm{~kg} /$ $\mathrm{m}^{2}$, estimated glomerular filtration rate (eGFR) $>60 \mathrm{ml} / \mathrm{min}$ (calculated using the Modification of Diet in Renal Disease (MDRD) equation), HbA1c $>7.5 \%(58 \mathrm{mmol} / \mathrm{mol})$ and treated with oral hypoglycaemic agents and/or insulin. Exclusion criteria were recent history of CVD, cancer, renal failure, liver disease or other chronic diseases as assessed by the investigator (26). CVD was defined as a previous history of MI, stroke, coronary or vascular surgery. Of the 464 patients screened for participation in the CIMT trial, 27 patients were not meeting the inclusion criteria, 11 patients declined to participate and 11 patients were not included due to other reasons. Thus, a total of 415 Danish patients with T2D were included and randomised, by central concealed randomization stratified for age (above 65 years), previous insulin treatment and treatment centre.

The results presented were obtained at the baseline investigation of the trial. Baseline measurements included clinical examinations, fasting blood and urine samples, carotid ultrasound scan and dual energy X-ray absorptiometry (DXA) scans. Serum total 25(OH)D (25-hydroxy vitamin D3 plus 25-hydroxy vitamin D2) was measured with an electro-chemiluminescence immunoassay (ECLIA) competitive assay using the Cobas e411, Roche equipment based on a one-step sandwich assay. This method was used as routine analyses in our hospital. All samples were measured in one batch using identical batch numbers. The coefficients of variation $(\mathrm{CV})$ for $25(\mathrm{OH}) \mathrm{D}$ was $6.4 \%$. Analytical sensitivity was of $10.0 \mathrm{nmol} / \mathrm{l}$. According to the Institute of Medicine vitamin D deficiency is defined as a $25(\mathrm{OH}) \mathrm{D}<50 \mathrm{nmol} / \mathrm{l}$, where treatment is recommended (27). 
Carotid IMT and arterial stiffness markers, DC and YEM, were measured by ultrasound scans of the carotid arteries and performed by the same two lab technicians. The CV as measured by the s.D. of the log-transformed values was $10 \%$ between sonographers and between days (28). After $10 \mathrm{~min}$ of rest in the supine position the scanning was performed using a GE Healthcare (Waukesha, WI, USA) logic 9 with a nine linear $(8 \mathrm{MHz})$ or a 12 linear $(12 \mathrm{MHz})$ probe, initially, a rough crosssectional scanning was made to localize possible plaques or stenosis. Peripheral blood pressure was measured with a validated oscillometric device measuring on the brachial artery on the dominant arm after $10 \mathrm{~min}$ of rest and immediately after ultrasound examination. We did not have the possibility to measure the central blood pressure in this study. Thereafter, a longitudinal scanning was made of the common carotid artery with storage of a dynamic sequence of 4-6s for the measurement of carotid IMT. For the border detection and calculations, we used specialized software (vascular tools 5, Medical Imaging Applications, Coralville, IA, USA). The region of interest was defined as a segment of the far wall in common carotid artery devoid of focal plaques and spanning 5-10 mm with a centre $10 \mathrm{~mm}$ proximal to the bulb. The mean carotid IMT was calculated as the average of the mean IMT of the left and right common carotid artery. Relative compliance (carotid artery DC (mmHg)) of the common carotid artery was automatically calculated as a measure of the change in vessel volume from systole to diastole calculated from the equation: (radius in systole ${ }^{2}$-radius in diastole ${ }^{2}$ )/(radius in diastole ${ }^{2} \times$ pulse pressure) where high/increased values are beneficial for the hemodynamic system. YEM ( $\mathrm{mmHg}$ ) reflects the intima-media layers tendency to be deformed elastically where low/reduced values are beneficial for the hemodynamic system.

Lumbar spine of L1-L4, total femur and femoral neck BMD was measured by DXA using a Hologic Discovery A, series 82800-A (Hologic, Bedford, MA, USA) and Software 12.6.2. $T$-scores referring to the Hologic database young normal mean BMD were calculated for each anatomical site. Osteopenia was defined as $T$-score below -1 but above -2.5 , and osteoporosis was defined as any $T$-score $\leq-2.5$ (29). Lumbar spine TBS was derived for each spine DXA examination via TBS Software (TBS iNsight Software, version 1.8; Med-Imaps, Pessac, France) installed on the Hologic machine. TBS was calculated as the mean value of the individual measurements for vertebrae L1-L4, based on gray-level analysis of DXA images. TBS calculation is performed over the same region of interest as the BMD measurement. Any fractured and/or arthritis vertebrae were excluded from computation.

Information on physical activity was obtained by questionnaires.

\section{Results}

Data were tested for normal distribution by QQ-plots and histograms. Baseline characteristics were compared using Student's $t$-test for continuous variables and $\chi^{2}$-test for categorical variables. Correlation analyses (Pearson/ Spearman's $\rho$ ) and multivariate linear regression analyses were performed in addition. The selection of covariates was based on two approaches. Relevant variables including age, sex, BMI, HbA1c, smoking, eGFR, systolic blood pressure and alendronate treatment, were significantly correlated to the dependent variables and selected. In addition, covariates reported in the literature were included (see 'Results' section). Data are presented as median (range) for $25(\mathrm{OH}) \mathrm{D}$ and mean ( \pm s.D.) or $n(\%)$ as appropriate and divided according to deficient and sufficient status of serum $25(\mathrm{OH}) \mathrm{D}$. A two-sided $P$ value $<0.05$ was considered statistical significant. The statistical software SPSS (version 19, IBM, Chicago, IL, USA) was used.

Baseline characteristics are shown in Table 1. In this population, carotid IMT was $0.793 \pm 0.137 \mathrm{~mm}, 43 \%$ of the patients had osteopenia and $3 \%$ had osteoporosis.

\section{Vitamin D (25(OH)D)}

The median concentration of $25(\mathrm{OH}) \mathrm{D}$ was $48(7-176)$ $\mathrm{nmol} / \mathrm{l}$ in the total group of patients with T2D $(n=415)$ and $214(52 \%)$ of the patients were $25(\mathrm{OH}) \mathrm{D}$ deficient $(<50 \mathrm{nmol} / \mathrm{l})$. No significant differences were found in $25(\mathrm{OH}) \mathrm{D}$ levels according to season $(P=0.15$, data not shown) or physical activity ( $P=0.149$, data not shown).

\section{Analyses in patients with and without vitamin D deficiency}

The vitamin D deficient patients were younger, had shorter duration of T2D, higher BMI, higher HbA1c, higher eGFR, lower systolic blood pressure and lower carotid IMT compared to the patients with sufficient levels of 25(OH)D in unadjusted analyses (see Table 1). Dividing data according to $25(\mathrm{OH}) \mathrm{D} \leq 37 \mathrm{nmol} / 1$ (as suggested in (18)) did not reveal any association in the overall results (data not shown).

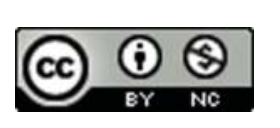

This work is licensed under a Creative Commons Attribution-NonCommercial 4.0 International License. 
Table 1 Baseline characteristics ${ }^{a}$

\begin{tabular}{|c|c|c|c|c|}
\hline Variables & All $(n=415)$ & 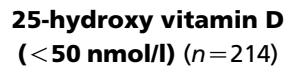 & $\begin{array}{c}\text { 25-hydroxy vitamin D } \\
(\geq \mathbf{5 0} \mathbf{~ n m o l} / \mathbf{l})(n=201)\end{array}$ & $P$ value $^{a}$ \\
\hline Sex (female), $n(\%)$ & $132(32)$ & $60(28)$ & $72(36)$ & 0.089 \\
\hline Age (years) & $60 \pm 9$ & $58 \pm 9$ & $62 \pm 8$ & $<0.001$ \\
\hline Insulin treatment, $n(\%)$ & $294(71)$ & $238(76)$ & $56(64)$ & 0.135 \\
\hline T2D duration (years) & $12 \pm 6$ & $12 \pm 6$ & $13 \pm 7$ & 0.029 \\
\hline BMI $\left(\mathrm{kg} / \mathrm{m}^{2}\right)$ & $32.2 \pm 4.2$ & $32.7 \pm 4.2$ & $31.5 \pm 4.1$ & 0.003 \\
\hline $\mathrm{HbA} 1 \mathrm{c}(\%) /(\mathrm{mmol} / \mathrm{mol})$ & $8.6 \pm 1.1 / 70 \pm 12$ & $8.7 \pm 1.1 / 72 \pm 12$ & $8.3 \pm 1.1 / 68 \pm 10$ & 0.001 \\
\hline eGFR (ml/min) & $128 \pm 44$ & $135 \pm 48$ & $120 \pm 32$ & $<0.001$ \\
\hline Systolic blood pressure $(\mathrm{mmHg})$ & $139 \pm 15$ & $137 \pm 15$ & $142 \pm 16$ & 0.004 \\
\hline Diastolic blood pressure $(\mathrm{mmHg})$ & $82 \pm 9$ & $83 \pm 9$ & $82 \pm 9$ & 0.232 \\
\hline Statin treatment, $n(\%)$ & $375(90)$ & $193(90)$ & $182(91)$ & 0.901 \\
\hline Total cholesterol $(\mathrm{mmol} / \mathrm{l})$ & $4.2 \pm 0.9$ & $4.2 \pm 1.0$ & $4.1 \pm 0.9$ & 0.697 \\
\hline Current smokers, $n(\%)$ & $63(15)$ & $37(17)$ & $26(13)$ & 0.195 \\
\hline Vitamin D 25(OH)D (nmol/l) & $48(7-176)$ & $31(7-49)$ & $68(50-176)$ & $<0.001$ \\
\hline Vitamin D supplement, $n(\%)$ & $76(18)$ & $26(12)$ & $50(25)$ & 0.001 \\
\hline Calcium supplement, $n(\%)$ & $55(13)$ & $15(7)$ & $40(20)$ & $<0.001$ \\
\hline Alendronate treatment, $n(\%)$ & $8(2)$ & $4(2)$ & $4(2)$ & 0.929 \\
\hline Carotid IMT $(\mathrm{mm})$ & $0.793 \pm 0.137$ & $0.771 \pm 0.133$ & $0.816 \pm 0.139$ & 0.001 \\
\hline $\mathrm{DC}(\mathrm{mmHg})$ & $0.0030 \pm 0.001$ & $0.0026 \pm 0.001$ & $0.0025 \pm 0.001$ & 0.236 \\
\hline YEM $(\mathrm{mmHg})$ & $2354 \pm 1037$ & $2318 \pm 1057$ & $2392 \pm 1016$ & 0.488 \\
\hline Previous CVD, $n(\%)$ & $80(19)$ & $65(20)$ & $15(17)$ & 0.611 \\
\hline Normal bone status, $n(\%)$ & $218(53)$ & $111(52)$ & $107(53)$ & 0.964 \\
\hline Osteopenia, $n(\%)$ & $177(43)$ & $92(46)$ & $85(42)$ & - \\
\hline Osteoporosis, $n(\%)$ & $13(3)$ & $7(3)$ & $6(3)$ & - \\
\hline Total femur $T$-score & $0.12 \pm 1.045$ & $0.19 \pm 1.074$ & $0.05 \pm 1017$ & 0.157 \\
\hline Total femur BMD $\left(\mathrm{g} / \mathrm{cm}^{2}\right)$ & $0.999 \pm 0.210$ & $0.100 \pm 0.202$ & $0.993 \pm 0.219$ & 0.611 \\
\hline Femoral neck $T$-score & $-0.5 \overline{9} \pm 1.0$ & $-0.58 \pm 0.951$ & $-0.60 \pm 1.051$ & 0.885 \\
\hline Femoral neck BMD $\left(\mathrm{g} / \mathrm{cm}^{2}\right)$ & $0.811 \pm 0.175$ & $0.811 \pm 0.165$ & $0.811 \pm 0.186$ & 0.986 \\
\hline Lumbar spine $T$-score & $0.09 \pm 1.542$ & $0.08 \pm 1.502$ & $0.10 \pm 1.589$ & 0.852 \\
\hline Lumbar spine BMD $\left(\mathrm{g} / \mathrm{cm}^{2}\right)$ & $1.067 \pm 0.227$ & $1.074 \pm 0.198$ & $1.058 \pm 0.254$ & 0.475 \\
\hline TBS (unit less) & $1.145 \pm 0.162$ & $1.134 \pm 0.167$ & $1.157 \pm 0.156$ & 0.154 \\
\hline
\end{tabular}

Carotid IMT, carotid intima-media thickness; DC, distensibility coefficient; YEM, Young's elastic modulus; CVD, cardiovascular disease; BMD, bone mineral density; TBS, trabecular bone score; eGFR, estimated glomerular filtration rate.

${ }^{a}$ Unadjusted difference between patients with vitamin D deficiency and sufficiency. Values are shown as means ( \pm s.D.), median (range) and $n$ (\%). Differences were assessed by Student's $t$-test (for continuous variables) and by the $\chi^{2}$-test (for categorical variables).

\section{Analyses in patients with and without vitamin D supplementation}

A total of $76(18 \%)$ patients received vitamin D supplement and had significantly higher 25(OH)D (62 (12-176) nmol/l) compared to the patients not receiving vitamin $\mathrm{D}$ supplement $(45$ (7-161) nmol/l) $(P<0.001)$. Patients receiving vitamin $\mathrm{D}$ supplement were older, had lower HbA1c, and higher cholesterol levels. A higher proportion of women received supplements (data not shown).

\section{Vitamin D (25(OH)D) and CVD risk}

25(OH)D was positively associated with carotid IMT $(P=0.002)$, however after adjustment for sex, age, BMI, smoking, systolic blood pressure, total cholesterol, HbA1c and eGFR, the association was no longer significant $(P=0.36)$ (see Table 2$)$. Dividing the patients according

http://www.endocrineconnections.org
$\begin{array}{lr}\text { DOI: } 10.1530 / \text { EC-15-0034 } 2015 \text { The authors } \\ \text { Published by Bioscientifica Ltd }\end{array}$

to vitamin D supplement did not reveal any association between 25(OH)D and carotid IMT (data not shown). Age and systolic blood pressure were significantly associated to carotid IMT, DC and YEM both in all patients and after exclusion of patients on vitamin $D$ supplement in the multivariate regression analyses $(P<0.001$, data not shown). 25(OH)D was negatively associated with DC $(P=0.05)$, but no significant association was found in the adjusted analyses $(P=0.61)$ (see Table 2$)$. No association was found between $25(\mathrm{OH}) \mathrm{D}$ and YEM (see Table 2).

\section{Vitamin D (25(OH)D) and bone health}

25(OH)D was not associated with total femur T-score, femoral neck $T$-score or lumbar spine $T$-score (see Table 2 ). Vitamin D status and TBS were positively associated $(P=0.02)$. After adjustment for sex, age, BMI, smoking, calcium supplement, alendronate treatment and eGFR

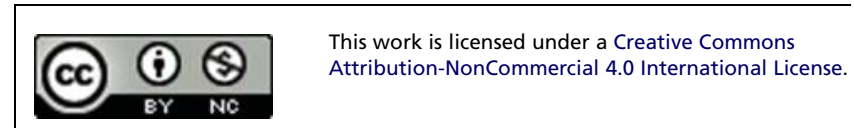


Table 2 Multivariate linear regression analyses ${ }^{\mathrm{a}}$.

\begin{tabular}{|c|c|c|c|}
\hline & \multicolumn{3}{|c|}{ 25(OH)D $(n=415)$} \\
\hline & $r$ & $P$ value & $\begin{array}{c}P \text { value }^{\mathrm{b}} \\
\text { (adjusted model) }\end{array}$ \\
\hline \multicolumn{4}{|l|}{ Bone health } \\
\hline Total femur T-score & -0.09 & 0.07 & 0.66 \\
\hline Femoral neck T-score & -0.03 & 0.56 & 0.68 \\
\hline Lumbar spine $T$-score & -0.04 & 0.37 & 0.59 \\
\hline TBS & 0.115 & 0.02 & 0.94 \\
\hline \multicolumn{4}{|l|}{ CVD risk } \\
\hline Carotid IMT & 0.15 & 0.002 & 0.36 \\
\hline DC & -0.10 & 0.05 & 0.61 \\
\hline YEM & 0.09 & 0.10 & 0.3 \\
\hline
\end{tabular}

TBS, trabecular bone score; carotid IMT, carotid intima-media thickness DC, distensibility coefficient; YEM, Young's elastic modulus.

a Differences between dependent and independent variables are tested with Spearman $\rho$ analyses and multivariate linear regression analyses.

${ }^{b}$ Analyses are adjusted for sex, age, BMI, smoking, calcium supplement, alendronate treatment and eGFR in the analyses with bone health as dependent variables. Analyses of CVD are adjusted for sex, age, BMI, smoking, systolic blood pressure, total cholesterol, eGFR and HbA1c.

this association was no longer significant $(P=0.94)$. Alendronate treatment and BMI were significantly positive associated with bone health, whereas smoking and bone health were negatively associated in the multiple regression analyses (data not shown).

No association was found between carotid IMT and any of the included measures of bone health.

\section{Discussion}

This study investigates the complex association between vitamin D, risk of CVD and bone health in a Danish cohort of obese patients with T2D. In contrast to previous studies in patients with or without T2D, no independent associations were found between vitamin $\mathrm{D}$ status and risk of CVD or bone health.

In the general population, two large cross-sectional studies have investigated the association between vitamin D status and risk of CVD, including measures of carotid IMT $(13,14)$, showing strong and independent positive relations between vitamin $\mathrm{D}$ deficiency (defined as $25(\mathrm{OH}) \mathrm{D}<50 \mathrm{nmol} / \mathrm{l})$ and subclinical as well as prevalent CVD, being persistent after adjustment for confounders. One study has also found a significant association between vitamin D levels and arterial stiffness (measured by pulse wave velocity) in a non-diabetic population (15). No studies have investigated the association between vitamin D status and the applied arterial stiffness markers, DC and YEM.

Similarly, several cross-sectional studies in the general population have found positive and significant associations between vitamin D levels and BMD measures $(30,31)$. However, these associations were not found in the current study.

In patients with $\mathrm{T} 2 \mathrm{D}$, the association between vitamin D status and carotid IMT has only been analysed in one study previously. This case-control study of 390 cases (T2D) and 390 controls (normoglycaemic) concluded that vitamin D deficiency (defined as serum 25(OH)D $\leq 37 \mathrm{nmol} / \mathrm{l}$ ) is more pronounced in patients with $\mathrm{T} 2 \mathrm{D}$ compared to controls, and showed a strong and independent association with increased carotid IMT after adjustment for similar covariates as in our study in addition to use of medication (18). Dividing our data according to $25(\mathrm{OH}) \mathrm{D} \leq 37 \mathrm{nmol} / \mathrm{l}$ did not reveal any differences in the results (data not shown). The main difference between the two studies is that patients in the present study are more obese, have lower vitamin D levels, thinner carotid IMT and more patients are on statin treatment (18). One study has investigated vitamin D levels and arterial stiffness (measured as pulse wave velocity) in 305 patients with T2D adjusted for similar covariates as in the current study, showing that low vitamin D status was associated with increased arterial stiffness (32). Our study suggests that in patients with $\mathrm{T} 2 \mathrm{D}$, the observed association between $25(\mathrm{OH}) \mathrm{D}$ and risk markers of CVD in the unadjusted analyses is primarily due to coexisting CVD risk factors, in particular age and systolic blood pressure.

Prospective cohort studies suggest that patients with T2D possess an overall higher risk of osteoporotic fractures compared to persons without T2D, despite normal BMD values (33). In patients with T1D predominantly normoweight decreased BMD has consistently been observed (34). The effect of vitamin D on bone health in patients with T2D is sparsely investigated. One study found that male T2D patients with a vitamin D level $<50 \mathrm{nmol} / 1 \mathrm{had}$ an increased risk of vertebral fractures, whereas this was not the case in women $(n=161)$, which could be due to a significantly higher proportion of men being smokers (35). In view of this study, it is notable that no significant association was found between vitamin D status and bone health in the present study. One possible explanation for this discrepancy could be the higher BMI in the present study since higher weight load seems beneficial for bone health, and patients included in the current study are markedly obese (BMI $>30 \mathrm{~kg} / \mathrm{m}^{2}$ ).

The strengths of the current study are the size of the study cohort and the applied measurements. The study cohort consisted of a well-defined group of patients with T2D. All patients had their primary outcome measurements (ultrasound and DXA scans) performed in a

This work is licensed under a Creative Commons Attribution-NonCommercial 4.0 International License. 
standardized manner in a single center to minimize variation. Since known CVD risk markers can only partly explain the increased risk of CVD in patients with T2D, assessing CVD risk markers by ultrasound scan is relevant although the method is currently only used for research purposes. Studies with longitudinal data of carotid IMT scans and clinical CVD outcomes in diabetic populations are needed. DXA scans are validated and considered the standard method to assess bone health, although BMDderived measures from DXA scans may not always detect a potential increased fracture risk (36). For analyses of patients with T2D, this discrepancy seems to be more pronounced as these patients tend to have a different bone structure than the general population (33). In an attempt to improve data strength TBS analyses were included. However, although patients TBS levels was slightly degraded (according to manufacturer) no association was found to levels of 25(OH)D.

One limitation is that assessing vitamin D status can be associated with measurement uncertainty. The ECLIA applied in this study was re-standardised before the analyses. One study concluded that status of vitamin D measured by the ECLIA disagreed considerably with other assays, and that the assay generally overestimates the vitamin $\mathrm{D}$ concentration (37) implying that the prevalence of vitamin D deficiency is underestimated. Another study compared the ECLIA with RIA and showed acceptable limits of agreement (38).

Another limitation is that the current study did not include measurements of biomarkers like adipokines or inflammatory cytokines which might be involved. Further and larger studies are required to address the impact of biomarkers on the association between atherosclerosis and CVD risk.

Notably, studies including people with T2D will always have several confounders, because of distinct heterogeneity among participants in relation to age, BMI, physical activity, duration and severity of diabetes including prevalence of late complications. Furthermore, the CVD risk factors are very aggressively treated in patients with T2D.

After adjustment for relevant covariates, 25(OH)D was not associated with carotid IMT, arterial stiffness, or bone health in this cross-sectional study of patients with T2D.

\section{Declaration of interest}

LLC, TA, AV, OP, TB, BC, SL, TJ and LT hold shares in Novo Nordisk A/S; LLC, TA, AV, TB, BGR, SL and LT report former employment by Novo Nordisk; BC is employed at Steno Diabetes Center, which is a diabetes hospital and academic institution owned by Novo Nordisk; SL holds shares in dynamically traded investment funds, which may own stocks from pharmaceutical companies; SL is an employee at Boehringer Ingelheim Pharma GmbH \& Co. KG, Ingelheim, Germany; SL's contribution was his alone and does not necessarily reflect the official position of Boehringer Ingelheim; AV has received fees from Novo Nordisk; TB is employed by Novo Nordisk A/S; BT is a member of an advisory board for Eli Lilly; OS has received fees from AstraZeneca, Sanofi, MSD, Boehringer-Ingelheim, Eli Lilly and Novo Nordisk; $\mathrm{CH}$ has received fees from Bristol-Myers Squibb, Sanofi and Novo Nordisk; LB has received fees from and attended advisory for Novo Nordisk A/S; SM has served as a consultant or adviser to Novartis Pharma, Novo Nordisk, Merck Sharp \& Dome, Sanofi-Aventis, AstraZeneca, Johnson \& Johnson, Rosche, Mankind, Astra-Zeneca, Boehringer-Ingelheim, Zeeland, Eli Lilly, Intarcia Therapeutics and Bristol-Meyer Squibb; SM has received fees for speaking from Novo Nordisk, Merck, Sharp \& Dome, Astra-Zeneca, Johnson and Johnson, Rosche, Shering-Ploug, SanofiAventis, Novartis Pharma, Eli Lilly, Bristol-Meyer Squibb and Boehringer Ingelheim. SM has received 2 research grants from Novo Nordisk. PE is a board member at Eli Lilly, MSD and Amgen; PE is part of the speakers bureau with Amgen and Eli Lilly. KW, BH, JW, CG, NW, MR, HV, ED, HP, TK, SS and EM have no conflicts of interests to declare.

\section{Funding}

The trial received an unrestricted grant from Novo Nordisk A/S for the submitted work.

\section{Acknowledgements}

The staff at the Clinical Research Unit at Steno Diabetes Center are thanked for their technical assistance. The CIMT trial group: Søren S Lund, Physician, Steno Diabetes Center, Denmark; Hans Perrild, Associate professor, Department of Endocrinology, Copenhagen University Hospital, Denmark; Thure Krarup, Chief Physician, Department of Endocrinology, Copenhagen University Hospital, Bispebjerg, Denmark; Ole Snorgaard, Chief Physician, Department of Endocrinology, Copenhagen University Hospital, Hvidovre, Denmark; Birthe Gade-Rasmussen, Chief Physician, Department of Endocrinology, Copenhagen University Hospital, Hvidovre, Denmark; Birger Thorsteinsson, Professor, Department of Cardiology, Nephrology and Endocrinology, Nordsjaellands Hospital, Denmark and Department of Medicine, Copenhagen University, Hellerup, Gentofte, Denmark; Michael Røder, Chief Physician, Department of Cardiology, Nephrology and Endocrinology, Nordsjaellands Hospital, Denmark and Department of Medicine, Copenhagen University, Hellerup, Gentofte, Denmark; Elisabeth R Mathiesen, Professor, Department of Endocrinology, Rigshospitalet, University of Copenhagen, Denmark; Tonny Jensen, Chief Physician, Department of Endocrinology, Rigshospitalet, University of Copenhagen, Denmark; Henrik Vestergaard, Chief Physician, Department of Endocrinology, Copenhagen University Hospital, Herlev, Denmark, Section of Metabolic Genetics, The Novo Nordisk Foundation Center for Basic Metabolic Research, and University of Copenhagen, Denmark; Christoffer Hedetoft, Chief Physician, Department of Medicine, University Hospital Køge, Denmark; Leif Breum, Chief Physician, Department of Medicine, University Hospital Køge, Denmark; Elsebeth Duun, Chief Physician, Department of Medicine, Copenhagen University Hospital, Gentofte, Denmark; Simone B Sneppen, Chief Physician, Department of Medicine, Copenhagen University Hospital, Gentofte, Denmark; Oluf Pedersen, Professor, Steno Diabetes Center, Denmark, Section of Metabolic Genetics, The Novo Nordisk Foundation Center for Basic Metabolic Research, and University of Copenhagen, Denmark; Bianca Hemmingsen, Physician, Copenhagen Trial Unit, Centre for Clinical Intervention Research, Rigshospitalet, Copenhagen University Hospital, Denmark and Department of Cardiology, Nephrology and Endocrinology, Nordsjaellands Hospital, Denmark; Sten Madsbad, Professor, Department of Endocrinology, Copenhagen University Hospital, Hvidovre, Denmark, and University of 
Copenhagen, Denmark; Christian Gluud, Head of Department, Copenhagen Trial Unit, Centre for Clinical Intervention Research, Rigshospitalet, Copenhagen University Hospital, Denmark; Jørn Wetterslev, Chief Physician, Copenhagen Trial Unit, Centre for Clinical Intervention Research, Rigshospitalet, Copenhagen University Hospital, Denmark; Allan Vaag, Professor, Steno Diabetes Center, Denmark and Department of Endocrinology, Rigshospitalet, University of Copenhagen, Denmark, and University of Copenhagen, Denmark.

\section{References}

1 Carstensen B, Kristensen JK, Ottosen P, Borch-Johnsen K \& Steering Group of the National Diabetes Register. The Danish National Diabetes Register: trends in incidence, prevalence and mortality. Diabetologia 200851 2187-2196. (doi:10.1007/s00125-008-1156-z)

2 Thaulow E, Erikssen J, Sandvik L, Erikssen G, Jorgensen L \& Cohn PF. Initial clinical presentation of cardiac disease in asymptomatic men with silent myocardial ischemia and angiographically documented coronary artery disease (the Oslo Ischemia Study). American Journal of Cardiology 199372 629-633. (doi:10.1016/0002-9149(93)90875-D)

3 Schramm TK, Gislason GH, Kober L, Rasmussen S, Rasmussen JN, Abildstrom SZ, Hansen ML, Folke F, Buch P, Madsen M et al. Diabetes patients requiring glucose-lowering therapy and nondiabetics with a prior myocardial infarction carry the same cardiovascular risk: a population study of 3.3 million people. Circulation $2008 \mathbf{1 1 7}$ 1945-1954. (doi:10.1161/CIRCULATIONAHA.107.720847)

4 Chambless LE, Folsom AR, Clegg LX, Sharrett AR, Shahar E, Nieto FJ, Rosamond WD \& Evans G. Carotid wall thickness is predictive of incident clinical stroke: the Atherosclerosis Risk in Communities (ARIC) study. American Journal of Epidemiology 2000151 478-487. (doi:10.1093/oxfordjournals.aje.a010233)

5 O'Leary DH, Polak JF, Kronmal RA, Manolio TA, Burke GL \& Wolfson SK Jr. Carotid-artery intima and media thickness as a risk factor for myocardial infarction and stroke in older adults. Cardiovascular Health Study Collaborative Research Group. New England Journal of Medicine 1999340 14-22. (doi:10.1056/NEJM199901073400103)

6 Sibal L, Agarwal SC \& Home PD. Carotid intima-media thickness as a surrogate marker of cardiovascular disease in diabetes. Diabetes, Metabolic Syndrome and Obesity: Targets and Therapy $2011423-34$. (doi:10.2147/DMSO.S8540)

7 Gepner AD, Colangelo LA, Blondon M, Korcarz CE, de Boer IH, Kestenbaum B, Siscovick DS, Kaufman JD, Liu K \& Stein JH. 25-Hydroxyvitamin D and parathyroid hormone levels do not predict changes in carotid arterial stiffness: the Multi-Ethnic Study of Atherosclerosis. Arteriosclerosis, Thrombosis, and Vascular Biology 2014 34 1102-1109. (doi:10.1161/ATVBAHA.113.302605)

8 Stern R, Tattersall MC, Gepner AD, Korcarz CE, Kaufman J, Colangelo LA, Liu K \& Stein JH. Sex differences in predictors of longitudinal changes in carotid artery stiffness: the Multi-Ethnic Study of Atherosclerosis. Arteriosclerosis, Thrombosis, and Vascular Biology 201535 478-484. (doi:10.1161/ATVBAHA.114.304870)

9 Simons PC, Algra A, Bots ML, Grobbee DE \& van der Graaf Y. Common carotid intima-media thickness and arterial stiffness: indicators of cardiovascular risk in high-risk patients. The SMART Study (Second Manifestations of ARTerial disease). Circulation 1999100 951-957. (doi:10.1161/01.CIR.100.9.951)

10 Khamdaeng T, Luo J, Vappou J, Terdtoon P \& Konofagou EE. Arterial stiffness identification of the human carotid artery using the stress-strain relationship in vivo. Ultrasonics 201252 402-411. (doi:10.1016/j.ultras.2011.09.006)

11 Van Belle TL, Gysemans C \& Mathieu C. Vitamin D and diabetes: the odd couple. Trends in Endocrinology and Metabolism 201324 561-568. (doi:10.1016/j.tem.2013.07.002)
12 Mosekilde L. Vitamin D requirement and setting recommendation levels: long-term perspectives. Nutrition Reviews 200866 (10 Suppl 2) S170-S177. (doi:10.1111/j.1753-4887.2008.00103.x)

13 Kendrick J, Targher G, Smits G \& Chonchol M. 25-Hydroxyvitamin D deficiency is independently associated with cardiovascular disease in the Third National Health and Nutrition Examination Survey. Atherosclerosis 2009205 255-260. (doi:10.1016/j.atherosclerosis.2008.10.033)

14 Carrelli AL, Walker MD, Lowe H, McMahon DJ, Rundek T, Sacco RL \& Silverberg SJ. Vitamin D deficiency is associated with subclinical carotid atherosclerosis: the Northern Manhattan study. Stroke 201142 2240-2245. (doi:10.1161/STROKEAHA.110.608539)

15 Giallauria F, Milaneschi Y, Tanaka T, Maggio M, Canepa M, Elango P, Vigorito C, Lakatta EG, Ferrucci L \& Strait J. Arterial stiffness and vitamin D levels: the Baltimore longitudinal study of aging. Journal of Clinical Endocrinology and Metabolism 201297 3717-3723. (doi:10.1210/ jc.2012-1584)

16 Cigolini M, Iagulli MP, Miconi V, Galiotto M, Lombardi S \& Targher G. Serum 25-hydroxyvitamin D3 concentrations and prevalence of cardiovascular disease among type 2 diabetic patients. Diabetes Care 200629 722-724. (doi:10.2337/diacare.29.03.06.dc05-2148)

17 Joergensen C, Reinhard H, Schmedes A, Hansen PR, Wiinberg N, Petersen CL, Winther K, Parving HH, Jacobsen PK \& Rossing P. Vitamin $\mathrm{D}$ levels and asymptomatic coronary artery disease in type 2 diabetic patients with elevated urinary albumin excretion rate. Diabetes Care 201235 168-172. (doi:10.2337/dc11-1372)

18 Targher G, Bertolini L, Padovani R, Zenari L, Scala L, Cigolini M \& Arcaro G. Serum 25-hydroxyvitamin D3 concentrations and carotid artery intima-media thickness among type 2 diabetic patients. Clinical Endocrinology 200665 593-597. (doi:10.1111/j.1365-2265. 2006.02633.x)

19 Oh J, Weng S, Felton SK, Bhandare S, Riek A, Butler B, Proctor BM, Petty M, Chen Z, Schechtman KB1 et al. 25(OH)2 vitamin D inhibits foam cell formation and suppresses macrophage cholesterol uptake in patients with type 2 diabetes mellitus. Circulation 2009120 687-698. (doi:10.1161/CIRCULATIONAHA.109.856070)

20 Sugden JA, Davies JI, Witham MD, Morris AD \& Struthers AD. Vitamin $\mathrm{D}$ improves endothelial function in patients with type 2 diabetes mellitus and low vitamin D levels. Diabetic Medicine 200825 320-325. (doi:10.1111/j.1464-5491.2007.02360.x)

21 Mosekilde L. Vitamin D and the elderly. Clinical Endocrinology 200562 265-281. (doi:10.1111/j.1365-2265.2005.02226.x)

22 Vestergaard P. Discrepancies in bone mineral density and fracture risk in patients with type 1 and type 2 diabetes - a meta-analysis. Osteoporosis International 20074 427-444. (doi:10.1007/s00198-006-0253-4)

23 Janghorbani M, Van Dam RM, Willett WC \& Hu FB. Systematic review of type 1 and type 2 diabetes mellitus and risk of fracture. American Journal of Epidemiology 2007166 495-505. (doi:10.1093/aje/kwm106)

24 Bonds DE, Larson JC, Schwartz AV, Strotmeyer ES, Robbins J, Rodriguez BL, Johnson KC \& Margolis KL. Risk of fracture in women with type 2 diabetes: the Women's Health Initiative Observational Study. Journal of Clinical Endocrinology and Metabolism 200691 3404-3410. (doi:10.1210/jc.2006-0614)

25 Leslie WD, Morin SN, Lix LM \& Majumdar SR. Does diabetes modify the effect of FRAX risk factors for predicting major osteoporotic and hip fracture? Osteoporosis International 201425 2817-2824. (doi:10.1007/ s00198-014-2822-2)

26 Lundby Christensen L, Almdal T, Boesgaard T, Breum L, Dunn E, Gade-Rasmussen B, Gluud C, Hedetoft C, Jarloev A, Jensen T et al. Study rationale and design of the CIMT trial: the Copenhagen Insulin and Metformin Therapy trial. Diabetes, Obesity \& Metabolism 200911 315-322. (doi:10.1111/j.1463-1326.2008.00959.x)

27 Holick MF, Binkley NC, Bischoff-Ferrari HA, Gordon CM, Hanley DA, Heaney RP, Murad MH, Weaver CM \& Endocrine Society. Evaluation, treatment, and prevention of vitamin D deficiency: an Endocrine Society clinical practice guideline. Journal of Clinical Endocrinology and Metabolism 201196 1911-1930. (doi:10.1210/jc.2011-0385) 
28 Lundby-Christensen L, Almdal TP, Carstensen B, Tarnow L \& Wiinberg N. Carotid intima-media thickness in individuals with and without type 2 diabetes: a reproducibility study. Cardiovascular Diabetology 20109 40. (doi:10.1186/1475-2840-9-40)

29 Schousboe JT, Shepherd JA, Bilezikian JP \& Baim S. Executive summary of the 2013 International Society for Clinical Densitometry Position Development Conference on bone densitometry. Journal of Clinical Densitometry 201316 455-466. (doi:10.1016/j.jocd.2013.08.004)

30 Bischoff-Ferrari HA, Dietrich T, Orav EJ \& Dawson-Hughes B. Positive association between 25 -hydroxy vitamin $\mathrm{D}$ levels and bone mineral density: a population-based study of younger and older adults. American Journal of Medicine 2004116 634-639. (doi:10.1016/j.amjmed. 2003.12.029)

31 Collins D, Jasani C, Fogelman I \& Swaminathan R. Vitamin D and bone mineral density. Osteoporosis International 19988 110-114. (doi:10.1007/BF02672505)

32 Lee JI, Oh SJ, Ha WC, Kwon HS, Sohn TS, Son HS \& Cha BY. Serum 25-hydroxyvitamin D concentration and arterial stiffness among type 2 diabetes. Diabetes Research and Clinical Practice 201295 42-47. (doi:10.1016/j.diabres.2011.09.006)

33 Carnevale V, Romagnoli E \& D'Erasmo E. Skeletal involvement in patients with diabetes mellitus. Diabetes/Metabolism Research and Reviews 200420 196-204. (doi:10.1002/dmrr.449)
34 Sealand R, Razavi C \& Adler RA. Diabetes mellitus and osteoporosis. Current Diabetes Reports 201313 411-418. (doi:10.1007/s11892-0130376-X)

35 Kim YJ, Park SO, Kim TH, Lee JH \& Kim SH. The association of serum 25-hydroxyvitamin D and vertebral fractures in patients with type 2 diabetes. Endocrine Journal 201360 179-184. (doi:10.1507/endocrj. EJ12-0269)

36 Amer MS, Khater MS, Omar OH, Mabrouk RA \& Mostafa SA. Association between Framingham risk score and subclinical atherosclerosis among elderly with both type 2 diabetes mellitus and healthy subjects. American Journal of Cardiovascular Disease 20144 14-19. (doi:10.4236/ wjcd.2014.41004)

37 van den Ouweland JM, Beijers AM, Demacker PN \& van Daal H. Measurement of 25-OH-vitamin D in human serum using liquid chromatography tandem-mass spectrometry with comparison to radioimmunoassay and automated immunoassay. Journal of Chromatography. B, Analytical Technologies in the Biomedical and Life Sciences 2010878 1163-1168. (doi:10.1016/j.jchromb.2010.03.035)

38 Jafri L, Khan AH, Siddiqui AA, Mushtaq S, Iqbal R, Ghani F \& Siddiqui I. Comparison of high performance liquid chromatography, radio immunoassay and electrochemiluminescence immunoassay for quantification of serum 25 hydroxy vitamin D. Clinical Biochemistry 201144 864-868. (doi:10.1016/j.clinbiochem.2011.04.020)

Received in final form 21 April 2015

Accepted 30 April 2015 http://www.endocrineconnections.org DOI: 10.1530/EC-15-0034
(C) 2015 The authors Published by Bioscientifica Ltd
This work is licensed under a Creative Commons Attribution-NonCommercial 4.0 International License. 